\title{
Trifuoroperacetic acid in consecutive Criegee rearrangement and carboxonium ions generation
}

\author{
Pavel A. Krasutsky* and Igor V. Kolomitsyn \\ Natural Resources Research Institute, University of Minnesota Duluth, Duluth, Minnesota \\ 55811, USA \\ E-mail:pkrasuts@nrri.umn.edu
}

Dedicated to Professor Nikolai Zefirov on his $\mathbf{7 0}^{\text {th }}$ birthday

(received 14 Mar 05; accepted 11 May 05; published on the web 18 May 05)

\begin{abstract}
Recent achievements in the use of trifluoroperacetic acid (TFPAA) in consecutive Criegee rearrangement are covered in this review. Consecutive Criegee rearrangement promoted by TFPAA represents a new approach to this classic method in organic chemistry. The concept of selective double and triple O-insertion is described through the analysis of kinetic data, the overview of synthetic examples and studies of the reaction mechanisms. TFPAA in trifluoroacetic acid (TFAA) media is introduced as a specific reagent for consecutive Criegee rearrangement and for stable carboxonium ion generation. Heterolytic decarboxylation and bisperfluoroacyl peroxide synthesis are discussed as miscellaneous and useful reactions.
\end{abstract}

Keywords: Criegee rearrangement, Baeyer-Villiger reaction, carboxonium ion, oxygen insertion, decarboxylation, peroxide, trifluoroperacetic acid

\section{Contents}

1. Introduction

2. Consecutive Criegee rearrangement

2.1 Discovery of consecutive Criegee rearrangement

2.2 Development of consecutive Criegee rearrangement with trifluoroperacetic acid (TFPAA)

2.3 Mechanism and carboxonium ions generation in consecutive criegee rearrangement.

3. Miscellaneous reactions

3.1 Heterolytic decarboxylation involving acyltrifluoroacetyl peroxides

3.2 Synthesis of bisperfluoroacyl peroxides

4. Summary

5. Acknowledgements

6. References 


\section{Introduction}

The Baeyer-Villiger ${ }^{1}$ reaction A (Scheme 1) has long been recognized as a powerful method for the oxidation of a ketone $\mathbf{1}$ to an ester or lactone. ${ }^{2,3}$ The treatment of aldehydes or ketones $\mathbf{1}$ with peracids always leads to the formation of hydroxyperesters 2 ("Criegee intermediate"). ${ }^{4}$ A consequent rearrangement of hydroxyperesters $\mathbf{2}$ leads to ester $\mathbf{3}$ as the final product. It is widely accepted $^{2,4}$ that Baeyer-Villiger reaction proceeds via a two-stage mechanism. The kinetic data suggests that either the addition ${ }^{5,6}$ of peracid to ketone $\mathbf{1}$ or peroxyester $\mathbf{2}$ rearrangements ${ }^{7}$ can be the rate-determining step. Criegee rearrangement $\mathbf{B},{ }^{8}$ on the other hand, is the ionic rearrangement of peroxyester $\mathbf{5}$ to ester $\mathbf{6}$, which can decompose to the final product $\mathbf{7}$. Criegee rearrangement can be performed in a solution starting from alcohols ${ }^{9}$ or their esters ${ }^{10}$ because intermediate peroxyesters can be generated in situ in the reaction media. Relative migration aptitude of different groups $(t-\mathrm{Bu}>\mathrm{i}-\mathrm{Pr}>\mathrm{Et}>\mathrm{Me})$ in the Baeyer-Villiger reaction ${ }^{11,12}$ and Criegee rearrangement ${ }^{12,13}$ and the $\rho$-value of the relative migration rates of substituted benzyl groups $\left(\rho=-2.1^{14,15}\right.$ for Criegee rearrangement and $\rho=-2.55^{16}$ for Baeyer-Villiger reaction with $\mathrm{H}_{3} \mathrm{PO}_{5}$ ) suggested that the group $\mathrm{R}$ is carrying a partial positive charge in the transition state in both cases (anionotropic rearrangements). The mechanisms of Baeyer-Villiger reaction $\mathbf{A}$ and Criegee rearrangement $\mathbf{B}$ are closely related via peroxyesters $\mathbf{2}$ and $\mathbf{5}$ rearrangement (Scheme 1).

A

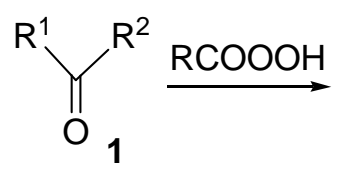<smiles>[R]OC([R])(O)C([R])O</smiles><smiles>[R]OC([R])=O</smiles>

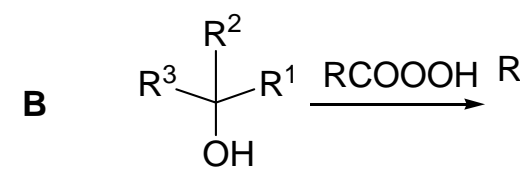

4<smiles>[R]OC([R])([R])OCC</smiles>

5<smiles>[R]OC([R])([R])O[R]CC</smiles>

6

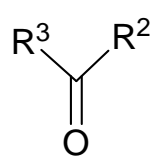

7

\section{Scheme 1}

Numerous reviews described the synthetic and mechanistic aspects of the Baeyer-Villiger reaction ${ }^{2,3,17,18}$ and Criegee rearrangement, ${ }^{9,12,19}$ but none have focused their attention on the consecutive Criegee rearrangement (Scheme 2). Research activity during the last ten years, however, has led to new synthetic applications of consecutive Criegee rearrangements that certainly warrant the need of the present review. These applications mostly utilized the principal synthetic difference between Baeyer-Villiger reaction and Criegee rearrangement processes. The Baeyer-Villiger reactions are always limited to a mono-O-insertion process and the sequential Oinsertion has never been reported in literature. The Criegee rearrangement does not have such a limitation. Acidic and anhydrous conditions of reaction media helps to stabilize the ester 6 (Scheme 2) or the corresponding carboxonium ion $\mathbf{9}$, which can react further with the next 
molecule of peracid to give peroxyester 10 and, therefore, the reaction may proceed by consecutive pathway through mono-, double- and triple O-insertion. Triple O-insertion may also be named as the ultimate $\mathrm{O}$-insertion, because active oxygen atoms from intermediate peresters 5, 10 and 13 are incorporated into all three C-C bonds. Scheme 2 is a generic summary of the idea of ultimate triple-O-insertion process with the formation of possible ionic and non-ionic intermediates. After the first O-insertion by the Criegee mechanism, the resulting ester 6 can react with peracid through carboxonium ion 9 to give perester 10. Perester 10 undergoes an ionic rearrangement by the Criegee mechanism to give ester 11 (second O-insertion product). Ester 11 can react with another molecule of peracid through carboxonium ion 12 to give perester 13, which undergoes a Criegee rearrangement to yield ester 14 (third O-insertion product).

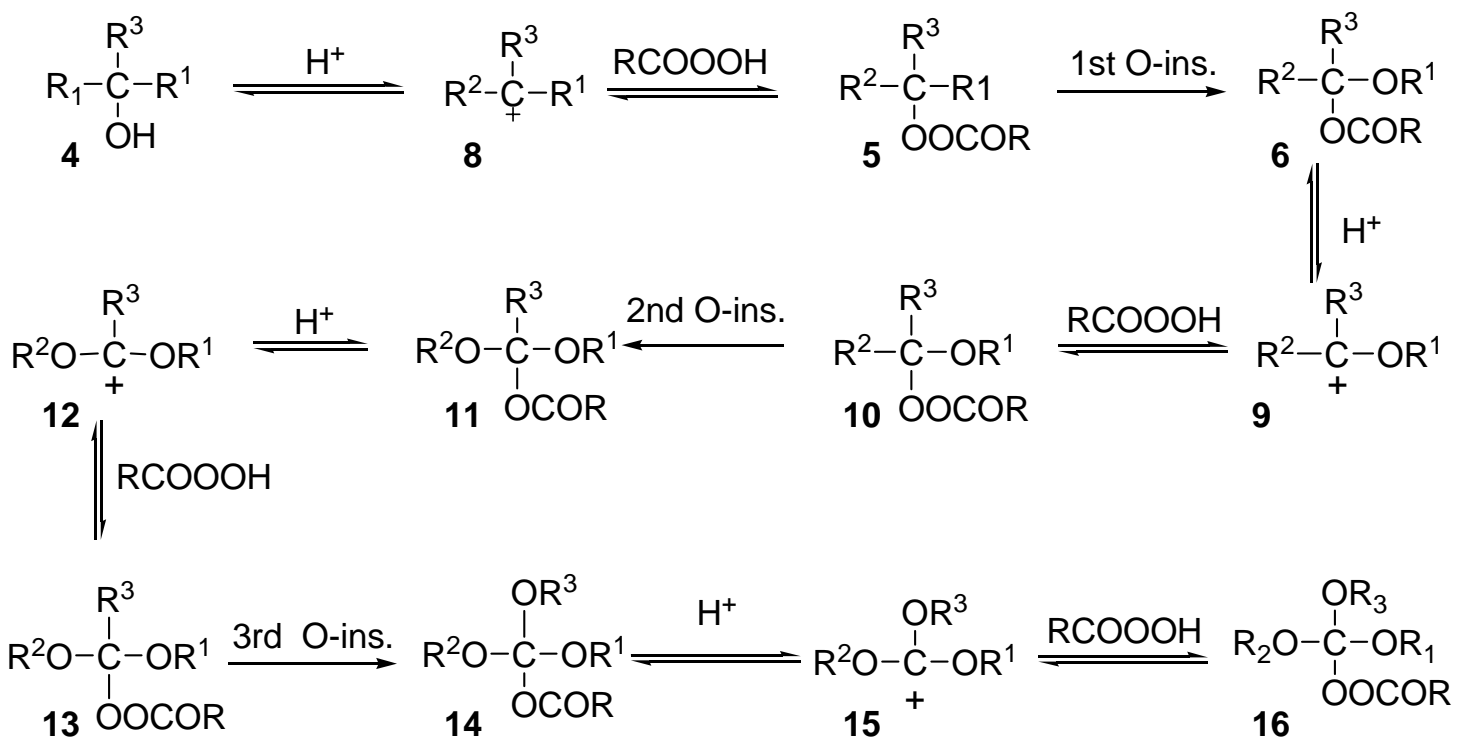

\section{Scheme 2}

The success of the triple O-insertion reaction will depend on the possibility of peroxyesters 5 , 10, 13 formation and the subsequent rearrangements. At each stage of O-insertion, however, esters 6, 11, 14 or the corresponding carboxonium ions 9, 12, 15 can decompose to give ketone 7, ester 17, or carbonate 18 correspondingly (Scheme 3), ${ }^{20}$ instead of reacting with the peracid. Ketone 7, ester 17, and carbonate 18 are therefore representing the mono-, double-, and triple Oinsertion products from alcohol 4. 


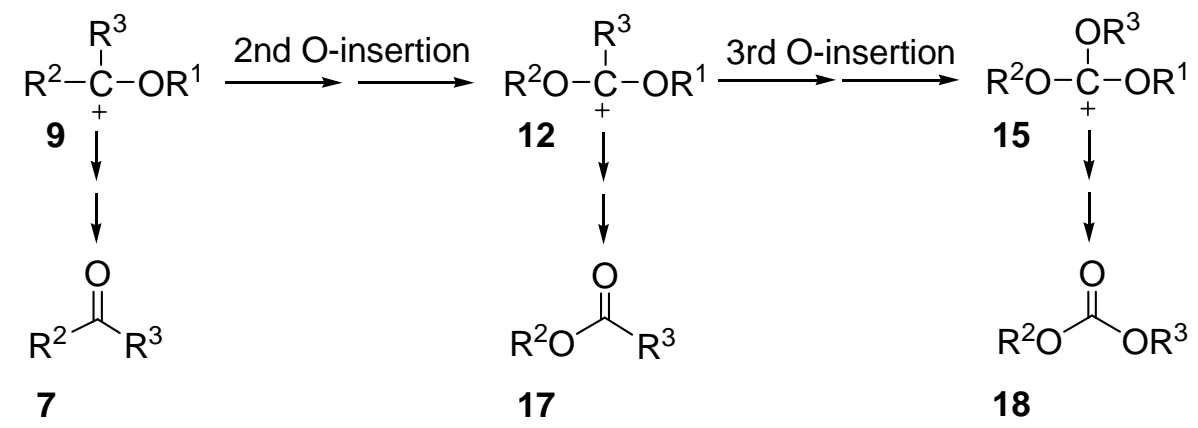

\section{Scheme 3}

Carboxonium ions 9, 12 and $\mathbf{1 5}$ are suitable intermediates for the ion exchanging process $\left(\mathrm{RCOO}^{-}\right.$and $\mathrm{RCOOO}^{-}$) in every step of the consecutive Criegee rearrangement (Scheme 2 and Scheme 3). Although the chemistry of carboxonium ions is a very well developed area, ${ }^{21}$ the generation of stable carboxionium ions in Criegee rearrangement has been reported only in strong $^{9}$ and super-acidic media. ${ }^{22.23}$ The previous decade brought new and mild conditions for carboxonium ion generation that deserves to be discussed.

This review specifically discusses current research efforts targeting the selective double- and triple O-insertion process in the Criegee rearrangement and selective generation of stable carboxonium ions.

\section{Consecutive Criegee Rearrangement}

\subsection{Discovery of consecutive Criegee rearrangement}

Historically, one of the earliest reports on the possible realization of the consecutive Criegee rearrangement came from the study of the reactions of p-nitroperbenzoic acid with 2,2dimethoxypropane (18) (Scheme 4). ${ }^{24}$

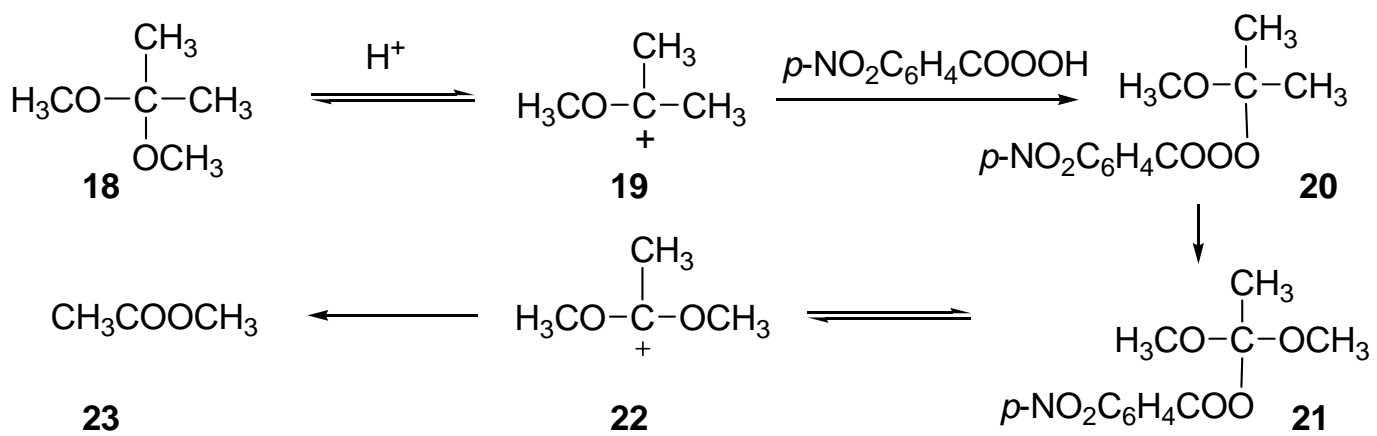

\section{Scheme 4}


While investigating the ionic rearrangement of 2-alkoxy-2-propyl p-nitroperbenzoates the authors found evidence of intermediate cation 22 formation (Scheme 4). This led to the idea of an alternative method of alkoxy perester generation in situ by treatment of ketals with peracids. When ketal 18 was treated with $p$-nitroperbenzoic acid in benzene with traces of sulfuric acid as a catalyst, a 47\% yield of methyl acetate (23) (a double oxygen insertion product) was obtained.

Methyl orthoacetate 24 with $p$-nitroperbenzoic acid was converted into dimethyl carbonate (25) (triple O-insertion product) with $48 \%$ yield (Scheme 5). ${ }^{24}$

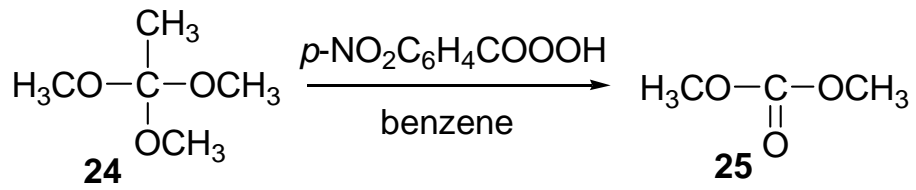

\section{Scheme 5}

Similar approaches were explored ${ }^{25,26}$ with cyclic ketals 26. The reaction of 2,7dioxabicyclo[2,2,1]heptanes 26 with $\mathrm{m}$-chloroperbenzoic acid (MCPBA) in $\mathrm{CCl}_{4}$ or $\mathrm{CH}_{2} \mathrm{Cl}_{2}$ yielded 2,7,8-trioxabicyclo[3,2,1] octanes 31 (double O-insertion products). The third final Oinsertion products were not detected (Scheme 6).

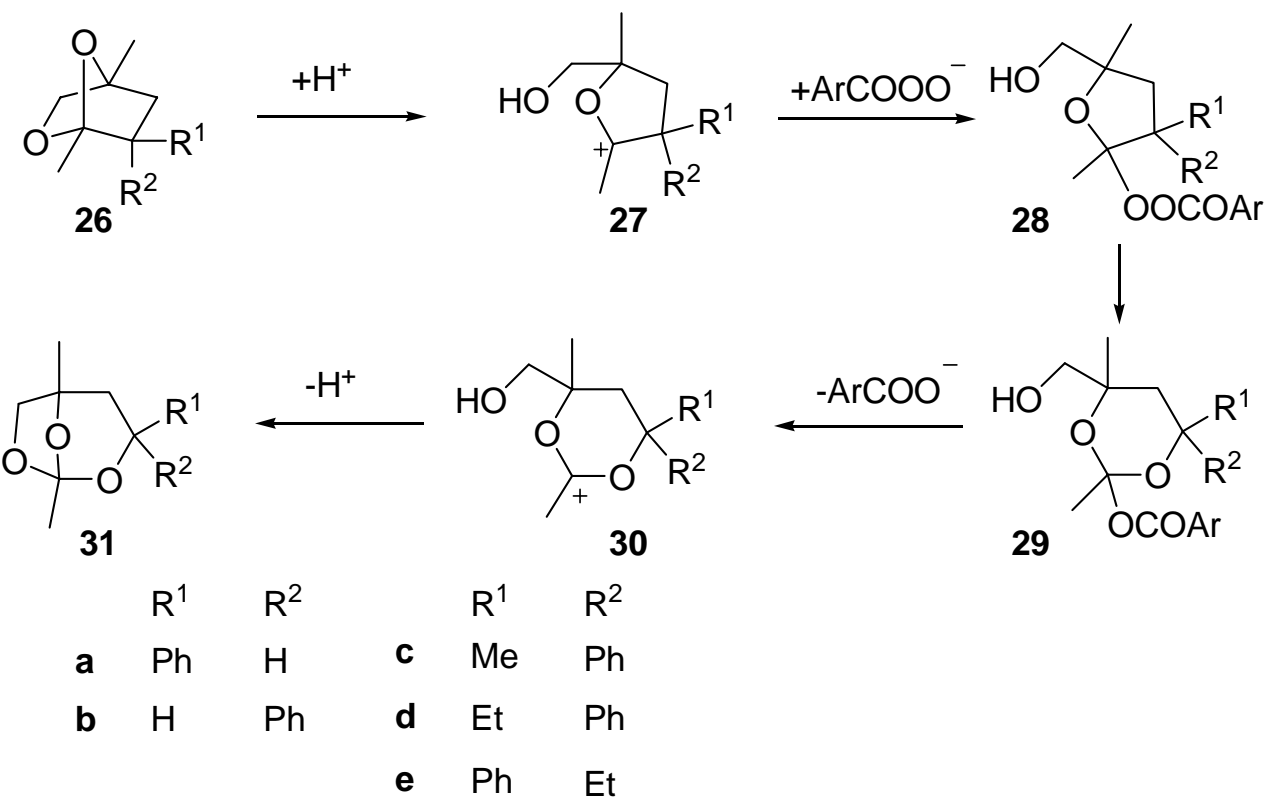

\section{Scheme 6}

These studies ${ }^{24-26}$ manifest the possibility of the generation of peroxyesters as the key intermediates in Criegee rearrangement from ketals and orthoesters and also support the idea of consecutive Criegee rearrangement. The reactions of ketals 32, 36, and 39 with an excess of 
MCPBA in $\mathrm{CH}_{2} \mathrm{Cl}_{2}$ yielding orthocarbonates 33, 37, 40 may be considered to be the first synthetic proof of the consecutive O-insertion. Heating of the reaction mixtures yielded tetrahydropyran (34) and tetrahydrofuran (38) as the products of ultimate Criegee rearrangement of ketals 32 and $36 .^{27,28}$ The reported formation of tetrahydropyran (34) and tetrahydrofuran (38) and diethyl carbonate 35 from orthocarbonates 36 and 37 revealed a new synthetic potential for an ultimate consecutive Criegee rearrangement (Scheme 7) that may be utilized for the synthesis of oxacycloalkane structures.<smiles>CCOC1(OCC)CCCCC1</smiles>

32<smiles>CCOC1(OCC)CCCC1</smiles>

36<smiles>CCOC(CC)(CC)OCC</smiles>

39<smiles>CCOC1(OCC)OCCCCCO1</smiles>

33<smiles>CCOC1(OCC)OCCCCO1</smiles>

37<smiles>CCOC(OCC)(OCC)OCC</smiles>

40<smiles>CCOC(=O)OCC</smiles>

34 35<smiles>CCOC(=O)OCC</smiles>

38

35

\section{Scheme 7}

Similarly, the ultimate consecutive O-insertion process was observed when polyhedral ketal 41 was treated with MCPBA in $\mathrm{CH}_{2} \mathrm{Cl}_{2}{ }^{29}$ Carbonate 42 and lactone 43 were obtained in this non-polar and low acidic media (Scheme 8). This process is very similar to the above mentioned studies when cyclic ketals were converted into orthocarbonates ${ }^{27,28}$ and into lactones. ${ }^{30}$
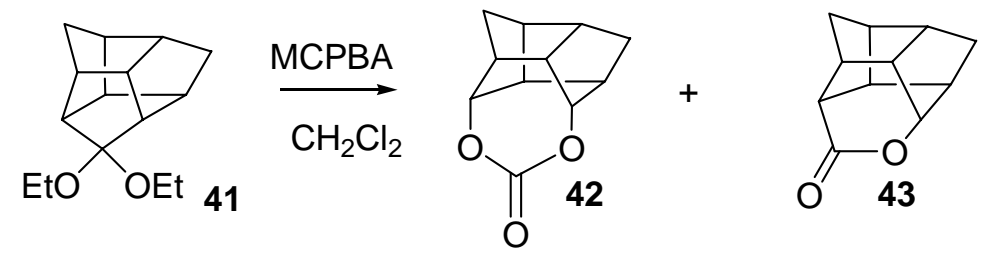

\section{Scheme 8}

The possibility to employ tertiary alcohols instead of hydroperoxides or ketals for the Criegee rearrangement was explored using cyclic alcohols 44 and $47 .{ }^{9}$ When alcohols 44 and 47 (Scheme 9) were treated with Caro acid, the formation of ketones $\mathbf{4 6}$ and $\mathbf{5 0}$ was observed. In 
both cases the ketones $\mathbf{4 6}$ and $\mathbf{5 0}$ resisted further transformations and were isolated as final products with yields above $90 \%$. The authors also found evidence of cation $\mathbf{4 5}$ and $\mathbf{4 8}$ formation. Therefore, in the case of tertiary alcohols oxidation in strong acidic condition $\left(\mathrm{H}_{2} \mathrm{SO}_{4}\right)$ the Criegee rearrangement occurred only with formation of mono-oxygen insertion products $\mathbf{4 5}$ and $\mathbf{4 8}$ or their corresponding ketones 46 and $\mathbf{5 0 .}$

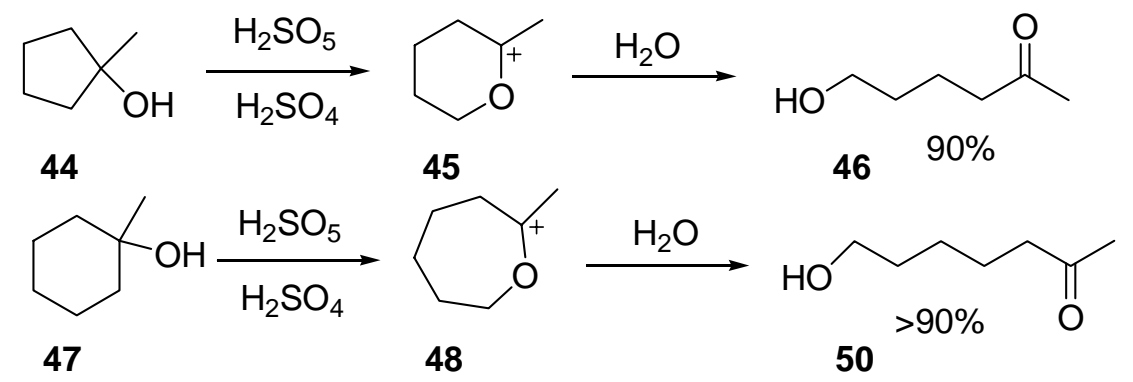

\section{Scheme 9}

The consecutive Criegee rearrangement was attempted using the strong acidic conditions, ${ }^{9}$ but was not achieved in spite of excess of Caro acid. The successful achievement of double- and triple- O-insertion in consecutive Criegee rearrangement was described in studies that use TFPAA in TFAA as the reaction media. ${ }^{10,20,31-35}$ The development of these reactions and their mechanisms will be discussed in the following sections.

\subsection{Development of consecutive Criegee rearrangement with trifluoroperacetic acid (TFPAA)}

A synthetic potential of the double and triple consecutive O-insertion was investigated for the reactions of organic substrates with trifluoropeacetic acid (TFPAA) in trifluoroacetic acid (TFAA). ${ }^{10,20,31-35}$

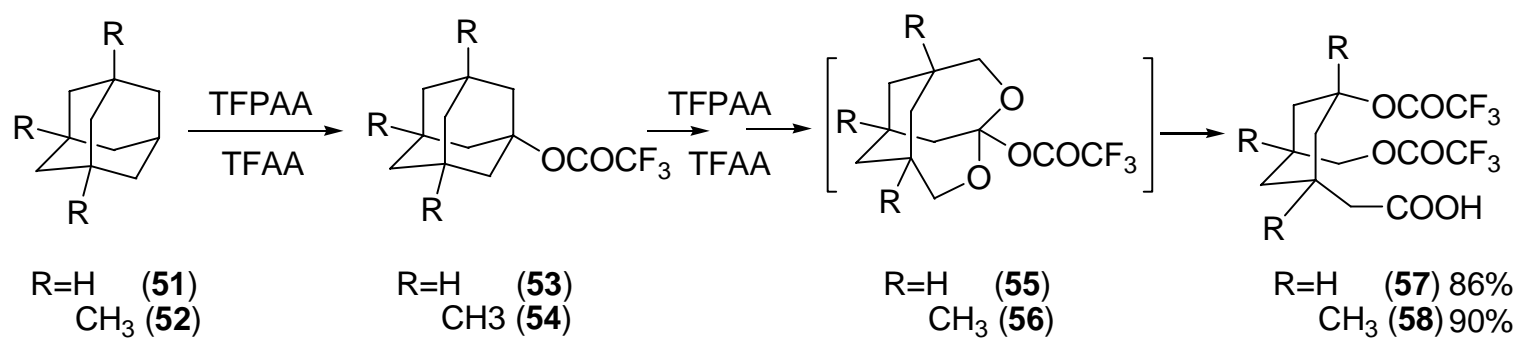

\section{Scheme 10}

The reaction of adamantane $(\mathbf{5 1})^{31}$ and 1,3,5-trimethyladamantane $(\mathbf{5 2})^{32}$ in the TFPAA/TFAA media led to the selective oxidative fragmentation at the bridgehead position of the adamantane structure (Scheme 10). The observed reaction is the first example of a selective 
double Criegee rearrangement process near tertiary carbon. The observed good yields of 1,3ditrifluroacetoxymethylcyclohex-5-yl acetic acid (57) and 1,3,5-trimethyl-1,3ditrifluoroacetoxymethylcyclohex-5-yl acetic acid (58) pointed to the high potential of this oxidative system for double consecutive oxygen insertion into polyhedral structures. The authors did not study the mechanism of this process, but the structure of the final products suggests the double Criegee rearrangement. The intermediate formation of 3,5-dioxadihomoadamant-4-yl trifluoroacetate (55) and 1,7,9-trimethyl-3,5-dioxadihomoadamant-4-yl trifluoroacetate (56) was also proposed. It is worth mentioning that the consecutive reaction was supported by the high ratio of TFPAA/substrate $=8-10$.

The other approach ${ }^{33}$ describes the formation of oxaadamantane (60) with a good yield (56\%) through the selective oxidative fragmentation of 2-methyl-2-hydroxyadamantane (59) (Scheme 11). The parallel formation of exo-2-hydroxy-4-oxaadamantane (61) was also attributed to the double Criegee rearrangement. The study ${ }^{33}$ has a definite mechanistic relation to the above mentioned processes of tetrahydrofuran (38) and tetrahydropyran (34) synthesis (Scheme 7).

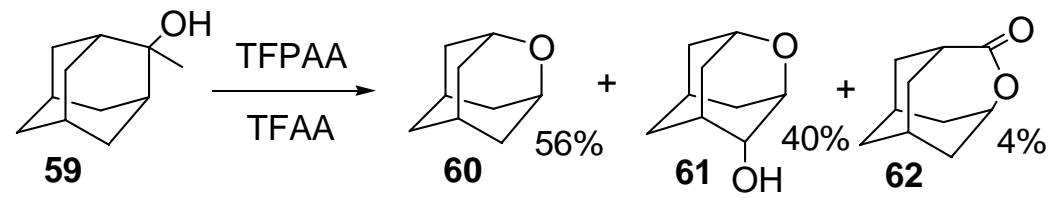

\section{Scheme 11}

When 2,2-dimethoxyadamantane (63) and 2,2-diethoxyadamantane (64) were used as the substrates (Scheme 12), only traces of oxaadamantane (60) were observed. ${ }^{10}$ This result becomes clearer after detailed consideration of the reaction mechanism. At this point it should be mentioned that oxaadamantane (60) is a product of ultimate O-insertion for ketals 63 and 64 . This proves the principal possibility of the ultimate $\mathrm{O}$-insertion process with TFPAA in TFAA.

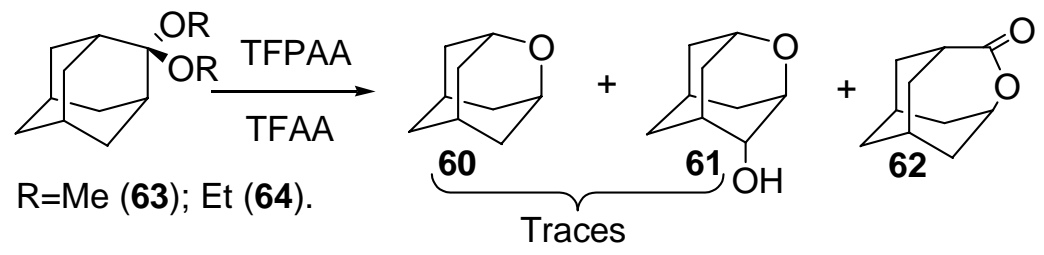

\section{Scheme 12}

A similar but less selective process was described in a stepwise conversion of 4-methyl-4hydroxyhomoadamantane (65) with TFPAA in TFAA. ${ }^{20}$ Products 67 and $\mathbf{6 8}$ are also resulting from the double consecutive Criegee rearrangement (Scheme 13). 


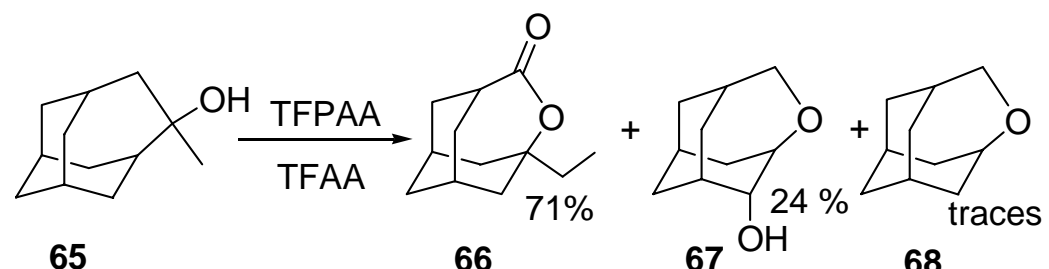

\section{Scheme 13}

When the polyhedral structure, exo-8-methyl-exo-2,6-tricyclo[5.2.1.0 $\left.0^{2,6}\right]$ decan-8-ol (69), was treated with TFPAA in TFAA at $0^{\circ} \mathrm{C}$, diester 70 was obtained with the yield of $95 \%$ as the only product of double Criegee rearrangement (Scheme 14). ${ }^{34}$
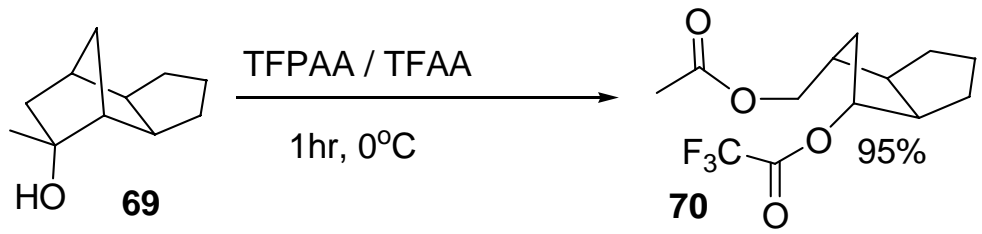

\section{Scheme 14}

The authors of a number of publications dealing with polyhedral molecules ${ }^{10,20,31-34}$ turned their attention to $t-\mathrm{BuOH}$ as an example of the simplest tertiary aliphatic alcohol. Because of the low migratory aptitude of the methyl group ${ }^{2,4,13}$, the consecutive Criegee rearrangement of trifluoroacetate 71 with TFPAA in TFAA was not observed at $-15^{\circ} \mathrm{C}$ and only peroxide 72 was formed. This observation is in contrast with the consecutive Criegee rearrangement of cage compounds. ${ }^{10,20}$ When temperature was increased to $5^{\circ} \mathrm{C}$, trifluoroperacetate 72 underwent double Criegee rearrangement with TFPAA in TFAA into methyl acetate (23) and methyl trifluoroacetate (76) (Scheme 15). ${ }^{35}$ The attempts to find traces of the third O-insertion product (dimethyl carbonate) were unsuccessful for these reaction conditions. 


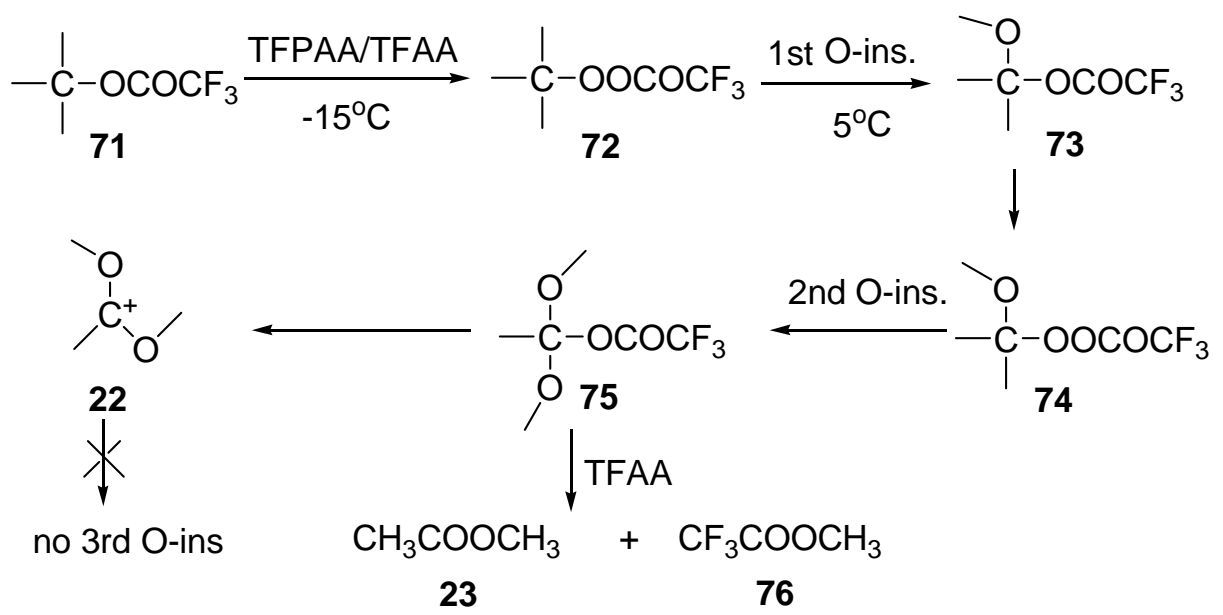

\section{Scheme 15}

The above described results led to the general conclusion that the tertiary alcohols $\left(\mathrm{R}^{1} \mathrm{R}^{2} \mathrm{R}^{3} \mathrm{COH}\right)$ or esters $\left(\mathrm{R}^{1} \mathrm{R}^{2} \mathrm{R}^{3} \mathrm{COCOCF}_{3}\right)$ undergo a double Criegee rearrangement with TFPAA in TFAA if $\mathrm{R}^{1}, \mathrm{R}^{2}$ or $\mathrm{R}^{3}$ are alkyl groups, or alkyl groups to be included in polyhedral structures. Until now, the selective triple O-insertion was not achieved for these molecules in TFAA with TFPAA.

Further development of this approach was explored with different triaryl methanols 77-80 (Scheme 16). This research led to ultimate triple O-insertion resulting in the synthesis of corresponding diaryl carbonates $\mathbf{8 1 - 8 4}$ with yields $90-96 \% .{ }^{35}$ The reaction products $\mathbf{8 1 - 8 4}$ are obviously the products of triple consecutive Criegee rearrangement process. This new one-step procedure leads to a simple practical way of diaryl carbonates synthesis (Scheme 16).

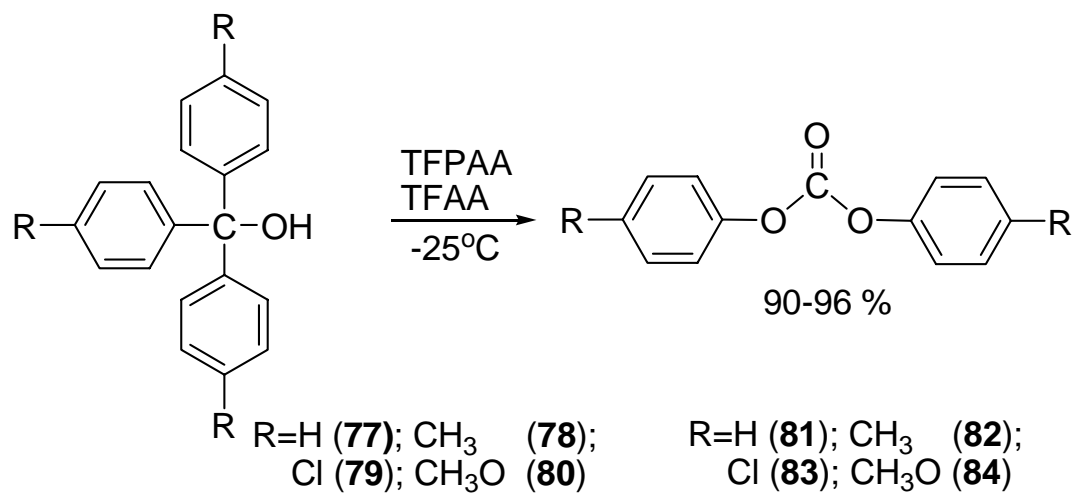

\section{Scheme 16}


Based on the above described results, the potential of consecutive Criegee rearrangement may be summarized as following:

1. Tertiary saturated alcohols (alicyclic, cyclic or polyhedral) or their esters undergo double Criegee rearrangement with TFPAA in TFAA.

2. Triarylmethanols or their esters undergo selective triple O-insertion (ultimate oxygen insertion) with the formation of diaryl carbonates with TFPAA in TFAA.

\subsection{Mechanisms and carboxonium ions generation in consecutive Criegee rearrangements}

The possibility of carboxonium ions generation via Criegee rearrangement was demonstrated by Olah and co-workers in superacidic media. ${ }^{22,23}$ It was shown that peroxyesters 85-87 undergo Criegee rearrangement at $-78^{\circ} \mathrm{C}$ with the formation of corresponding carboxonium ions $\mathbf{1 9}, \mathbf{8 8}$ (Scheme 17).

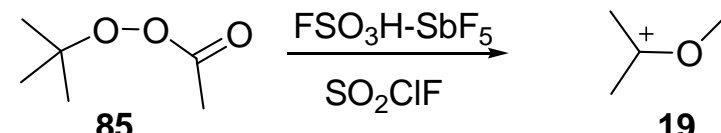

85<smiles>CC(C)(C)OOC(=O)Pc1ccccc1</smiles>

86

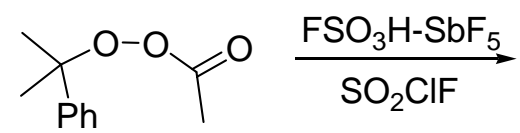

87
19

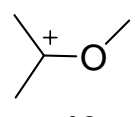

19<smiles>C[C](C)O[PbH]c1ccccc1</smiles>

88

\section{Scheme 17}

Since it has been known that carboxonium ions can be synthesized from orthoesters in trifluoroacetic acid (TFAA), ${ }^{36}$ an attempt to detect carboxonium ion formation during consecutive Criegee rearrangement was made in TFPAA/TFAA system. ${ }^{10}$ Thus, the low temperature conditions $\left(-25^{\circ} \mathrm{C}\right)$ allowed the ${ }^{1} \mathrm{H}$ and ${ }^{13} \mathrm{C}$ NMR observation of the stable double Oinsertion carboxonium ion [5-methyl-4,6-dioxabishomo-adamant-5-yl carbocation (90)] when 2methyl-2-hydroxyadamantane (59) was treated with TFPAA in TFAA (Scheme 18). When temperature was increased up to $10^{\circ} \mathrm{C}$, the proton elimination occurred with the formation of endo-3-acetoxybicyclo[3.3.1]-nonane-6-ene (91), which underwent either proton-catalyzed cyclization to oxaadamantane (60) or epoxidation and then proton-catalyzed cyclization to endo4-hydroxy-2-oxaadamantane (61). This is the first example of observation of carboxonium ion 92 in consecutive Criegee rearrangement in trifluoroacetic acid. It is worth mentioning that the described reaction (Scheme 18) is the best way of oxaadamantane (60) synthesis. ${ }^{10,33}$ Other ways of oxaadamantane $(\mathbf{6 0})$ synthesis were broadly presented in previous studies. ${ }^{37}$ 


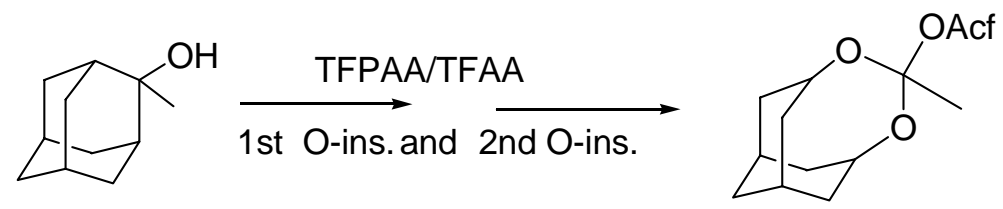

59
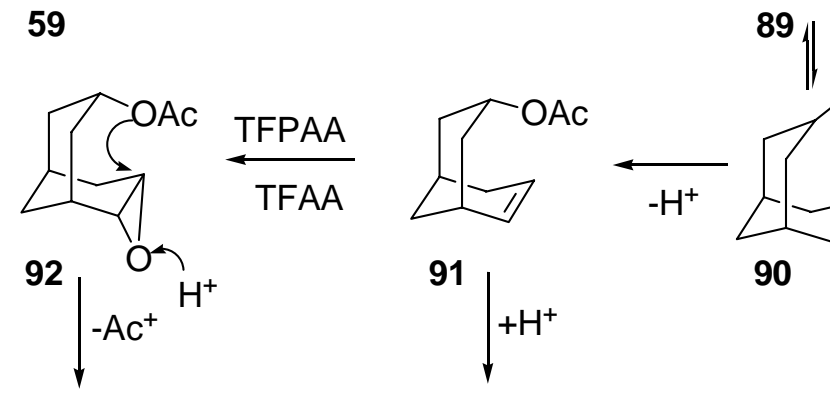

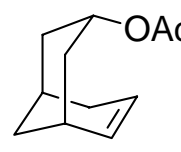

91<smiles>[Y][PH2+]1[CH]CCC1</smiles>

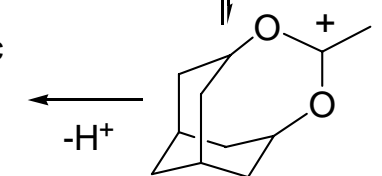

90

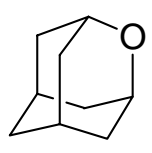

60
61

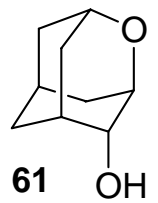

93

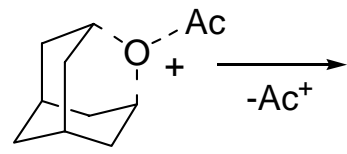

$$
\mathrm{Ac}_{\mathrm{f}}=\mathrm{CF}_{3} \mathrm{CO}
$$

\section{Scheme 18}

An analogous mechanism had been proposed for the double consecutive Criegee rearrangement of 4-methylhomoadamantan-4-ol (65) with TFPAA in TFAA (Scheme 19). ${ }^{20}$ Dioxacarboxonium cation 95 was not observed because of its high strain energy and, therefore, fast decomposition to final products 67 and 68. The corresponding $a b$ initio theoretical calculations were used to support the assumption of high strain energy of cation $\mathbf{9 5}$. The structure of observed products 67, 68 and kinetic data ${ }^{20}$ indicates that alcohol 65 undergoes the consecutive double Criegee rearrangement with TFPAA in TFAA. 


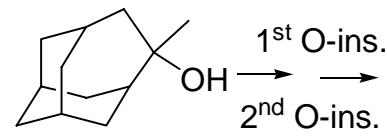

65
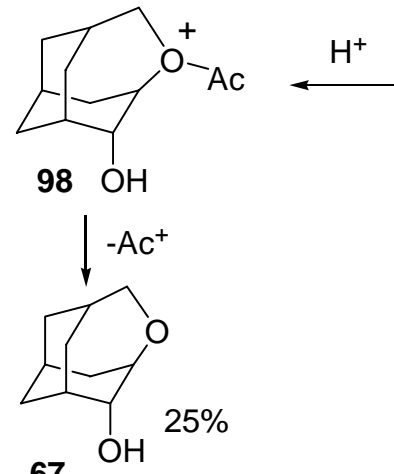

67

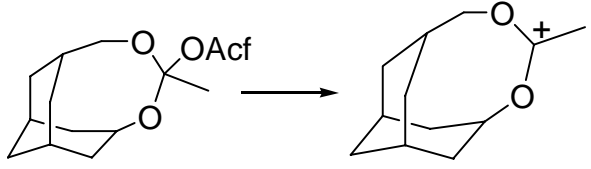

94

$95 \downarrow-\mathrm{H}^{+}$
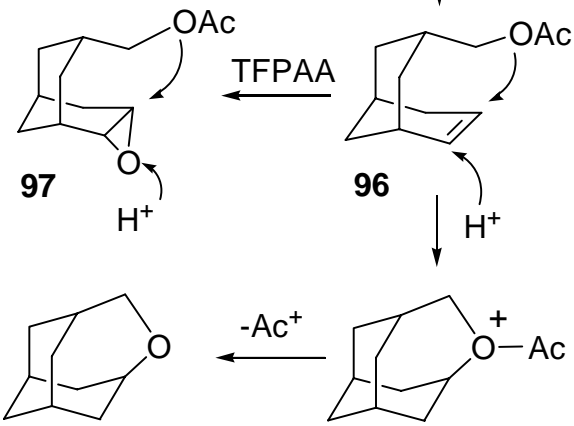

68 (traces)

99

\section{Scheme 19}

The study of the mechanism of consecutive Criegee rearrangement with tert-butyl trifluoroacetate (71) (Scheme 20) and triarylmethyl trifluoroacetates 77-80 avoided the previously mentioned complications due to proton elimination because of the nature of R-groups (methyl or aryl). ${ }^{35}$ The Criegee rearrangement of trifluoroacetate 71 with 10 -fold excess of TFPAA in TFAA at $5^{\circ} \mathrm{C}$ proceeds with the formation of an equivalent amount of the double Oinsertion products methyl acetate 23 and methyl trifluoroacetate 76. The formation of the intermediate 1,1-dimethoxyethyl cation (22) was detected at $-25^{\circ} \mathrm{C}$ by ${ }^{1} \mathrm{H}$ and ${ }^{13} \mathrm{C} \mathrm{NMR}$ after stirring of the reaction mixture for $2 \mathrm{hrs}$ at $5^{\circ} \mathrm{C}$ and then cooling down to $-25^{\circ} \mathrm{C}$. The observation of carboxonium ion 22 supports the assumption that the ionic form of cation 22 is more stable than the two other possible non-ionic forms of trifluoracetate $\mathbf{7 5}$ or of trifluoroperacetate $\mathbf{1 0 0}$ in the reaction media of TFPAA/TFAA, and this stabilization by TFPAA/TFAA media can create a sufficient energetic barrier to the third O-insertion process.

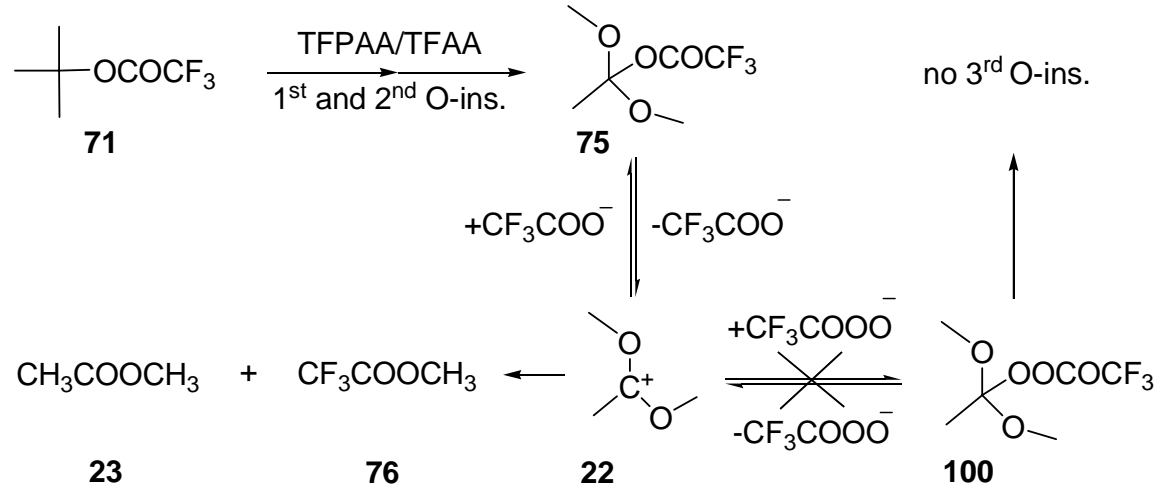

\section{Scheme 20}


A kinetic study of peresters decomposition ${ }^{13,24}$ shows that the reaction rate of Criegee rearrangement depends on the presence of a non-migrating alkoxy group (Scheme 21, Table 1). The Criegee rearrangement of peroxyesters 101-104 proceeds as a first-order reaction. The reaction rate of 2-methoxy-2-propyl $p$-nitroperbenzoate (104) is comparable to the reaction rate of 2-benzyl-2-propyl p-nitroperbenzoate (103) (Table 1). It is known ${ }^{2}$ that the migration aptitude of $\mathrm{CH}_{3}$-group is much lower than that of the benzyl group. A comparable reaction rate can be interpreted only by the influence of the $\mathrm{CH}_{3} \mathrm{O}$-group in a transition state of Criegee rearrangement for perester 104. The same may be concluded from the comparison of kinetic data for peresters 101 and 104. For measuring the reaction rate of the perester 101 rearrangement $^{13}$ the authors had to use an acetic acid media instead of $\mathrm{CH}_{3} \mathrm{OH}$. It should be noted that from the data analysis of Table 1 the reaction rate for $\mathrm{CH}_{3}$-group migration in perester $\mathbf{1 0 1}$ is $9.81 \times 10^{2}$ times slower than in perester $104\left(k_{108} / \mathrm{k}_{105}=9.81 \times 10^{2}\right)$. This can be explained by the partial positive charge stabilization with $\mathrm{CH}_{3} \mathrm{O}$-group in transition state. This data is also in an agreement with $\rho$-value of the relative migration rates of substituted benzyl groups $(\rho=-2.1)^{14,15}$ for Criegee rearrangement, as well as with the theoretical calculations for the Baeyer-Villiger reaction. $^{38}$ Therefore, the reaction rate of ionic decomposition of peroxyesters should be increased with increasing number of oxygen atoms attached to the $\mathrm{C}^{1}$-atom of the peroxide molecule (Table 1). This analysis is rather important for consideration of the mechanism of the consecutive Criegee rearrangement.

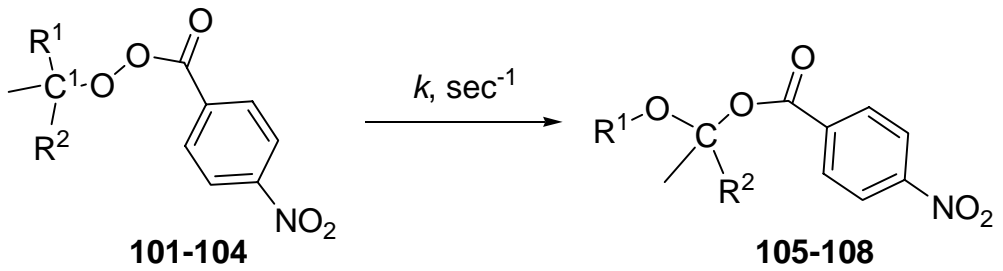

\section{Scheme 21}

Table 1. Rates of Decomposition of p-Nitroperbenzoates 105-108 (Scheme 21)

\begin{tabular}{cccccc}
\hline Entry & $\mathrm{R}^{1}$ & $\mathrm{R}^{2}$ & Solvent & $\mathrm{T},{ }^{\circ} \mathrm{C}$ & $k, \mathrm{sec}^{-1}$ \\
\hline $101^{\mathrm{a}}$ & $\mathrm{CH}_{3}$ & $\mathrm{CH}_{3}$ & $\mathrm{AcOH}$ & 50 & $1.04 \pm 0.09 \times 10^{-7}$ \\
$102^{\mathrm{a}}$ & $i-\mathrm{Pr}$ & $\mathrm{CH}_{3}$ & $\mathrm{CH}_{3} \mathrm{OH}$ & 50 & $2.55 \pm 0.03 \times 10^{-4}$ \\
$103^{\mathrm{a}}$ & $\mathrm{PhCH}_{2}$ & $\mathrm{CH}_{3}$ & $\mathrm{CH}_{3} \mathrm{OH}$ & 50 & $1.36 \pm 0.01 \times 10^{-4}$ \\
$104^{\mathrm{b}}$ & $\mathrm{CH}_{3}$ & $\mathrm{OCH}_{3}$ & $\mathrm{CH}_{3} \mathrm{OH}$ & 50 & $1.02 \times 10^{-4}$ \\
\hline
\end{tabular}

a. Data were taken from ref. 13. ${ }^{\text {b. }}$ Data were taken from ref. 24.

The kinetic results mentioned in Table 1 allow to suppose that the third O-insertion process should occur faster than the second O-insertion process and the second O-insertion process should occur faster than the first O-insertion process $\left(k_{3}>k_{2}>k_{1}\right)$. However, the experimental 
results with TFPAA in TFAA show that the consecutive O-insertion occurs for ester $\mathbf{7 1}$ with the formation of cation 22, which is the double oxygen insertion product. In accordance with kinetic results the reaction should proceed with the formation of the triple O-insertion. The absence of a third oxygen insertion process can be explained only by sufficient stabilization of cation 22 blocking the peroxyester $\mathbf{1 0 0}$ formation (Scheme 20). This explanation is also appropriate for the observation of only mono-oxygen insertion products ${ }^{9} 45$ and 48 with Caro acid in $\mathrm{H}_{2} \mathrm{SO}_{4}$ (Scheme 9). However, additional data is still needed for the generalization of this assumption.

Highly selective triple O-insertion with triarylmethanols 109 (Scheme 22) has been recently reported. ${ }^{35}$ Any attempt to stabilize the carboxonium ions 111 in TFAA has failed. This reaction proceeds with the formation of carbonate $\mathbf{1 1 3}$ in a high yield (triple O-insertion products). It was demonstrated earlier that the relative stabilities in the methyl- and phenyl-substituted delocalized carbocations decrease when a methyl group is replaced by a phenyl group. ${ }^{39}$ Kinetic results (Table 1) and the decrease in stability ${ }^{39,40}$ of cation 111 (Scheme 20) explains the easier formation of perester 112 and subsequent third O-insertion to carbonates 113.

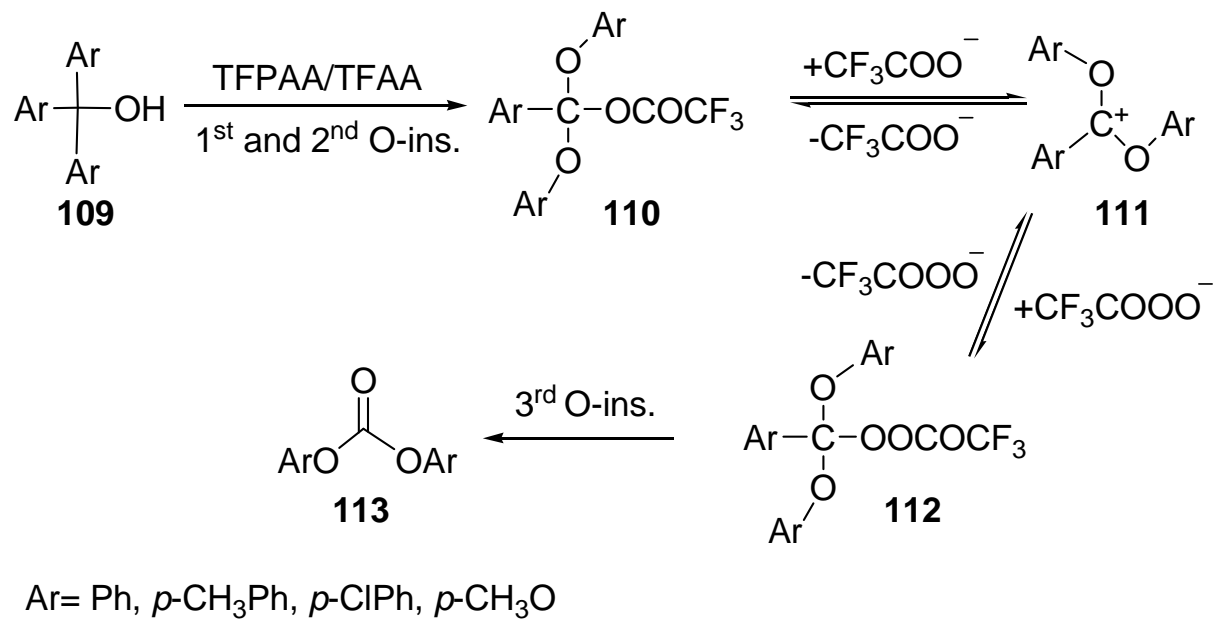

\section{Scheme 22}

The analogous mechanism interpretation may be also appropriate to the result that was obtained with benzophenone diethyl ketal (114) (Scheme 23). ${ }^{35}$ Ketal 114 undergoes the consecutive Criegee rearrangement at $-25^{\circ} \mathrm{C}$ with the formation of ethyl phenyl carbonate (119). In contrast with the consecutive Criegee rearrangement of 109 (Scheme 22), the authors found evidence of cation 116 formation. It should be noted that the presence of the ethyl group in 116 is stabilizing ${ }^{39,40}$ cation 116 and, therefore, slowing down the formation of perester $\mathbf{1 1 8 .}$ 


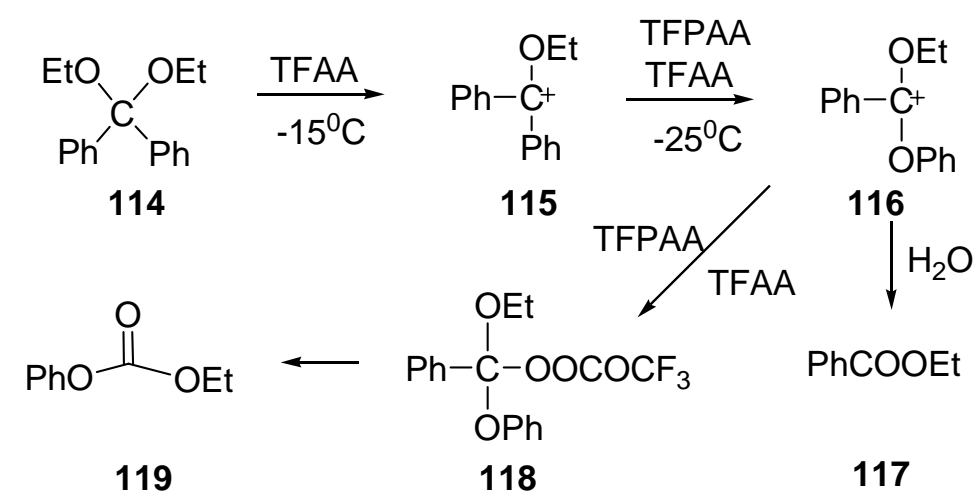

Scheme 23

\subsection{Miscellaneous Reactions}

\subsection{Heterolytic decarboxylation involving acyltrifluoroacetyl peroxides}

The remarkable behavior of trifluoroacetyl peresters in the Baeyer-Villiger reaction ${ }^{2}$ and Criegee rearrangement ${ }^{10}$ has found potential practical use in decarboxylation process involving the acyltrifluoroacetyl peroxide intermediates. ${ }^{41}$ Two methods were developed for in situ synthesis of acyltrifluoroacetyl peroxides (Scheme 24) and their decarboxylation. ${ }^{41}$ Both methods give a solution of acyltrifluoroacetyl peroxides 124 in TFAA. The process of decarboxylation was observed with excellent yields for all acyltrifluoroacetyl peroxides 124 with $\mathrm{R}$ tending to the formation of $\mathrm{R}^{+}$. When $\mathrm{R}=\mathrm{Me}$ (acetic acid) or $\mathrm{Ph}$ (benzoic acid), the process of ionic decarboxylation was not observed.

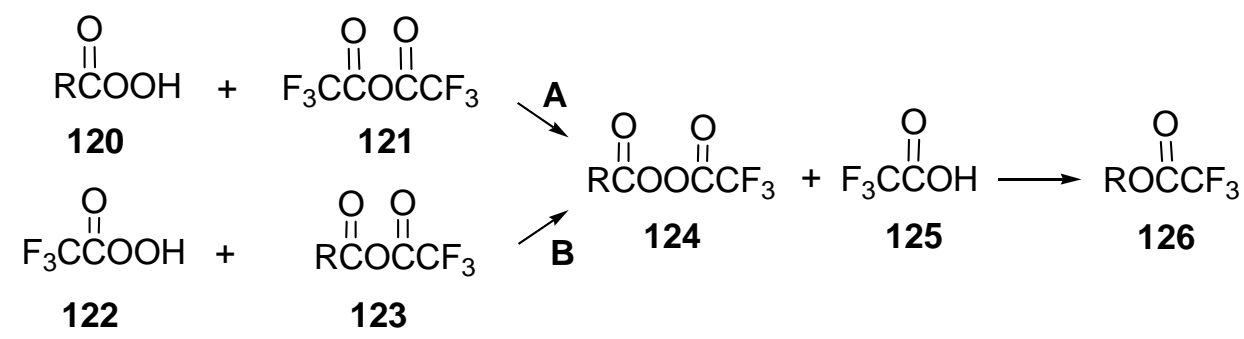

\section{Scheme 24}

Generation of carbocations in the reaction of decarboxylation is supported by the observation of the ring expansion process for peroxides 127 and 131 (Scheme 25) decomposition. The observed ring expansion is attributed to a heterolytic proton-catalyzed mechanism of intermediate peroxides 127 and 131 decomposition (Scheme 25). Moreover, the ratios 130:129= $91: 5,^{42,43}$ and $\mathbf{1 3 4}: \mathbf{1 3 3}=39: 54$ typically correspond to a kinetically-controlled reaction, ${ }^{43}$ that proceeds through carbocationic intermediates like 128 and $132 .^{44,45}$ 

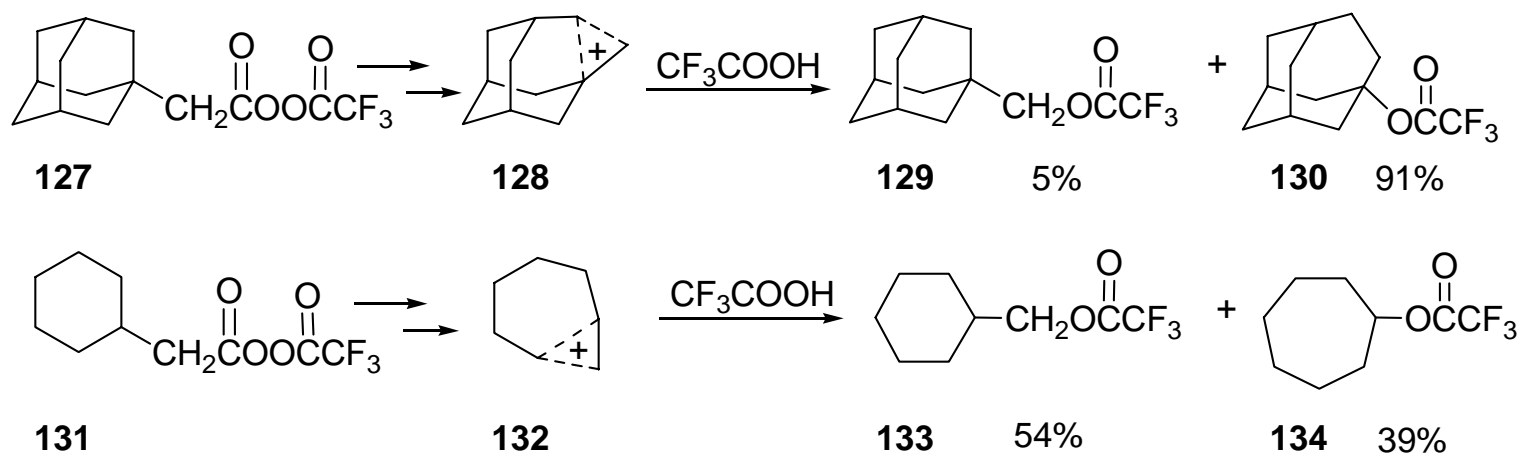

\section{Scheme 25}

\subsection{Synthesis of bisperfluoroacetylperoxides}

The reaction of perfluoroacyl anhydrides 135 with hydrogen peroxide revealed a good nucleophilic reactivity of peracids $\mathbf{1 3 6}$ when a catalytic amount of sodium or potassium trifluoroacetate was used (Scheme 26). ${ }^{46,47,48}$ This reactivity was useful in the synthesis of bisperfluoroacyl peroxides 138, which are used as reagents for radical perfluoroalkylation (for example, trifluoromethylation) and as radical initiators of polymerization. ${ }^{49,50}$

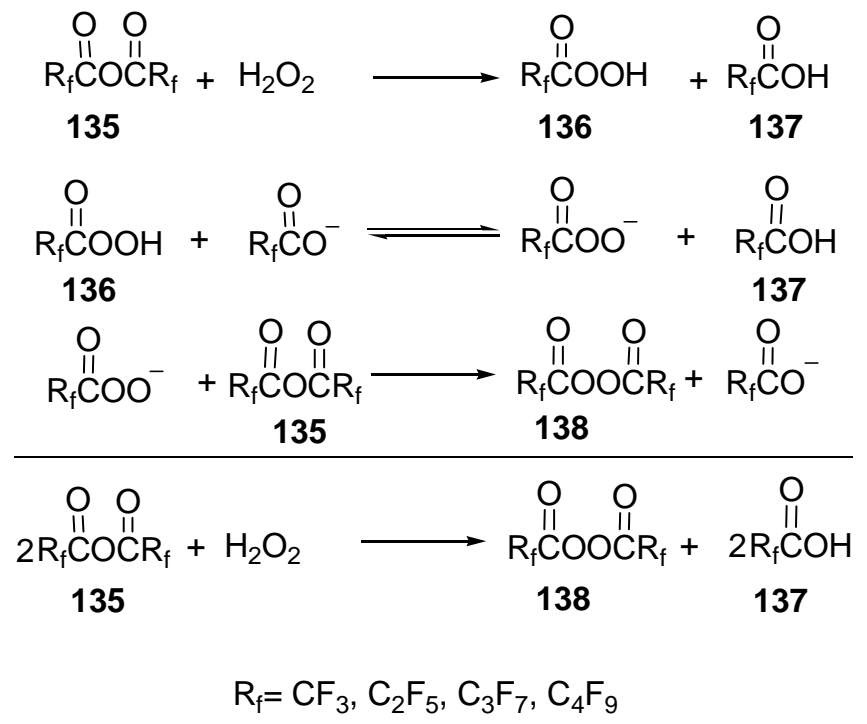

\section{Scheme 26}

A catalytic method of synthesis of bisperfluoroacyl peroxides 138 (Scheme 26) was developed using perfluoroacyl anhydrides 135 and hydrogen peroxide in the presence of a catalytic amount of the carboxylate $\mathrm{R}_{\mathrm{f}} \mathrm{COO}^{-} \mathrm{M}^{+}$. This reaction did not occur in the absence of catalyst. ${ }^{46}$ The efficiency of the basic catalysis in this process is a result of the higher 
nucleophilicity of perfluoropercarboxylate ion $\left(\mathrm{R}_{\mathrm{f}} \mathrm{COOO}^{-}\right)$that is formed in situ compared to the corresponding perfluoropercarboxylic acid 136.

It is important to emphasize that bistrifluoroacetyl peroxides $138\left(\mathrm{R}_{\mathrm{f}}=\mathrm{CF}_{3}\right)$ have a remarkable stability in trifluoroacetic acid. Thus, the concentration of a $28 \%$ solution of bistrifluoroacyl peroxide in trifluoroacetic acid remained almost unchanged (2\% of loss of bistrifluoroacetyl peroxide estimated by ${ }^{19} \mathrm{~F}$ NMR) at $-10^{\circ} \mathrm{C}$ for 6 months. This makes the $25-30 \%$ solutions of bistrifluoroacetyl peroxide in trifluoroacetic acid practically useful as a reagent for laboratory and industrial applications.

Acetyltrifluoroacetyl peroxide 141 was stable in the described reaction conditions and did not decarboxylate (Scheme 24). ${ }^{41}$ It can also be synthesized by the reaction of peracetic acid 139 with trifluoroacetic anhydride 121 (Scheme 27, A) or by the reaction of trifluoroperacetic acid 122 with acetyltrifluoroacetyl anhydride 140 (Scheme 27, B).

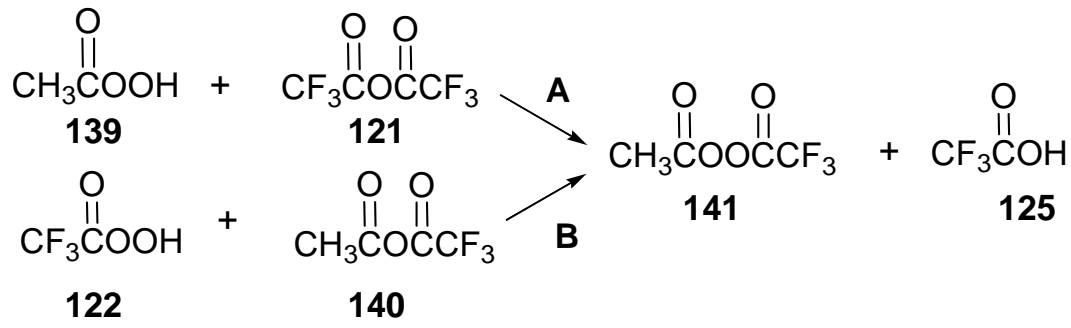

\section{Scheme 27}

It should be noted that both methods $\mathbf{A}$ and $\mathbf{B}$ (Scheme 27) do not require any basic catalysis.

\section{Summary}

We have attempted to summarize recent advances in the consecutive Criegee rearrangement utilizing trifluoroperacetic acid (TFPAA) in trifluoroacetic acid (TFAA) as an appropriate reagent and reaction media for the consecutive O-insertion into alcohols, ketals and their esters.

- Experimental data manifested that saturated aliphatic and polycyclic/polyhedral alcohols underwent a selective double O-insertion consecutive Criegee rearrangement process.

- The generation of stable carboxonium ions (dialkoxycarbonium ions) could be achieved by the reaction of tertiary alcohols and their esters with TFPAA in TFAA.

- The stabilization of dialkoxycarbonium ions in TFPAA/TFAA media results in the selective double O-insertion process for saturated aliphatic and polycyclic/polyhedral alcohols.

- Selective triple O-insertion has taken place for triaryl methanols in TFPAA/TFAA media. This peculiarity opens the way for the synthesis of diaryl carbonates with excellent yields. 
- Acyltrifluoroacyl peroxides in trifluoroacetic media underwent the unique process of heterolytic decarboxylation. This may be considered as a new heterolytic way of carboxylic acid decarboxylation through carbocation generation.

- One-step synthesis of bisperfluoroacyl peroxides is accomplished by mixing the corresponding bisperfluoroacyl anhydride and hydrogen peroxide at the presence of catalytic amount of corresponding $\mathrm{R}_{\mathrm{f}} \mathrm{COO}^{-} \mathrm{M}^{+}(\mathrm{M}=\mathrm{Na}$ or $\mathrm{K}){ }^{47,48}$

\section{Acknowledgements}

We thank Dr. Viktor V. Zhdankin for fruitful discussion and useful comments. Authors are also grateful to Jonathan Lee for his outstanding technical assistance.

\section{References}

1. Baeyer, A; Villiger, V. Ber. 1899, 32, 3625. (b) Baeyer, A; Villiger, V. Ber. 1900, 33, 858.

2. Krow, G. R. Org. React. 1993, 43, 251.

3. Mihovilovic, M. D.; Rudroff, F.; Groetzl, B. Current Org. Chem. 2004, 8, 1057.

4. Renz, M.; Meunier, B. Eur. J. Org. Chem. 1999, 737.

5. Ogata, Y.; Sawaki, Y. J. Am. Chem. Soc. 1972, 94, 4189.

6. Ogata, Y.; Sawaki, Y. J. Org. Chem. 1972, 37, 2953.

7. Palmer, B. W.; Fry, A. J. Am. Chem. Soc. 1970, 92, 2580.

8. (a) Criegee, R. Chem. Ber. 1944, 77, 722. (b) Criegee, R. Liebigs Ann. Chem. 1948, 560, 127.

9. Deno, N. C. B.; Wilbur, E.; Kramer, Kenneth E.; Lastomirsky, Robert R. J. Org. Chem. 1970, 35, 3080.

10. Krasutsky, P. A.; Kolomitsyn, I.V.; Kiprof, P.; Carlson, R. M.; Fokin, A. A. J. Org. Chem. 2000, 65, 3926.

11. Hawthorne, M. F.; Emmons, W. D.; McCallum, K. S. J. Am. Chem. Soc. 1958, 80, 6393.

12. Sawaki, Y. In Organic Peroxides. Ando, W., Ed.; John Wiley \& Sons: New-York, 1992; pp 425-477.

13. Hedaya, E.; Winstein S. J. Am. Chem. Soc. 1967, 89, 1661.

14. Wistuba, E.; Ruechardt, C. Tetrahedron Lett. 1981, 22, 3389.

15. Langhals, H.; Range, G.; Wistuba, E.; Ruechardt, C. Chem. Ber. 1981, 114, 3813.

16. Ogata, Y.; Tomizawa, K.; Ikeda, T. J. Org. Chem. 1978, 43, 2417.

17. Brink, G. J. T.; Arends, I. W. C. E.; Sheldon, R. A. Chem. Rev. 2004, 104, 4105.

18. Krow, G.R. Tetrahedron. 1981, 37, 2697.

19. Goering, H. L.; Olson, A. J. Am. Chem. Soc. 1953, 75, 5853.

20. Krasutsky, P. A.; Kolomitsyn, I.V.; Kiprof, P.; Carlson, R. M.; Sydorenko, N. A., Fokin, A. A. A. J. Org. Chem. 2001, 66, 1701. 
21. Olah, G. A.; Laali, K. K.; Wang, Q.; Prakash, G. K. S. Onium Ions; John Wiley \& Sons: New-York, 1998; pp 269-345.

22. Olah, G. A.; Parker, D. G.; Yoneda, N. Angew. Chem., Int. Ed . 1978, 17, 909.

23. Olah, G. A.; Parker, D. G.; Yoneda, N. J. Org. Chem. 1977, 42, 32.

24. Hedaya, E.; Winstein S. Tetrahedron Lett. 1962, 563.

25. Gaoni, Y. J. Chem. Soc. C 1968, 2925.

26. Gaoni, Y. J. Chem. Soc. C 1968, 2934.

27. Bailey, W. F.; Shih, M. J. J. Am. Chem. Soc. 1982, 104, 1769.

28. Bailey, W. F.; Bischoff, J. J. J. Org. Chem. 1985, 50, 3009.

29. Marchand, A. P.; Kumar, V. S.; Hariprakasha, H. K. J. Org. Chem. 2001, 66, 2072.

30. (a) Cossy, J.; Ranaivosata, J.-L.; Gille, B.; Belosta, V. Tetrahedron Lett. 1999, 40, 4681. (b) Sugimura, T.; Fujiwara, Y.; Tai, A. Tetrahedron Lett. 1999, 40, 4681.

31. Krasutsky, P. A.; Baula, O. P.; Yurchenko, A. G. Russ. J. Org. Chem. 1994, 30, 370.

32. Krasutsky, P. A.; Baula, O. P.; Botov, E. M. Russ. J. Org. Chem. 1996, 32, 1225.

33. Krasutsky, P. A.; Kolomitsin, I. V.; Carlson, R. M.; Jones, M. Jr. Tetrahedron Lett. 1996, 37, 5673.

34. Kolomitsin, I. V.; Sidorenko, N. A.; Krasutskii, P. A.; Yurchenko, A. G.; Fokin, A. A. Rus. J. Org. Chem. 2000, 36, 438.

35. Krasutsky, P. A.; Kolomitsyn, I. V.; Krasutsky, S. G.; Kiprof, P. Org. Lett. 2004, 6, 2539.

36. Ramsey, B. G.; Taft, R. W. J. Am. Chem. Soc. 1966, 88, 3058.

37. (a) Marchand, A. O.; Kumar, S.; Hariprakasha, H. K. J. Org. Chem. 2001, 66, 2072. (b) Wishnok, J. S.; Schleyer, P. von R.; Funke, E.; Pandit, G. D.; Williams, R. O.; Nickon, A. J. Org. Chem. 1973, 38, 539. (c) Black, R. M.; Gill, G. B.; Hands, D. J. Chem Soc. Chem Commun. 1972, 31. (d) Fish, M; Smallcombe, S.; Gramain, J. C.; McKervey, M. A.; Anderson, J. E. J. Org. Chem. 1970, 35, 1886. (f) Steter, H.; Tacke, P. Chem. Ber. 1963, 96, 694.

38. Reyes, L.; Castro, M.; Cruz, J.; Rubio, M. J. Phys. Chem. A 2005, 109, 3383.

39. Larsen, J. W.; Bouis, P. A.; Riddle, C. A. J. Org. Chem. 1980, 45, 4969.

40. For references on the decrease in stabilities of triaryloxycarbenium ions compare to trialkoxycarbenium ions see: (a) Kandanarachchi, P.; Sinnott, M. L. J. Am. Chem. Soc. 1994, 116, 5592. (b) Kandanarachchi, P.; Sinnott, M. L. J. Am. Chem. Soc. 1994, 116, 5601. (c) Kandanarachchi, P.; Sinnott, M. L. J. Chem. Soc., Chem. Commun. 1992, 777.

41. Krasutsky, P. A.; Kolomitsyn, I. V.; Botov, E. M.; Carlson, R. M.; Semenova, I. G.; Fokin, A. A. Tetrahedron Lett. 2002, 43, 8687.

42. Krasutsky, P. A.; Semenova, I. G.; Safronova, E. E.; Novikova, M. I.; Yurchenko, A. G. Zh. Org. Khimii. 1989, 25, 11, 2336.

43. This ratio of trifluoroacetates is expected for nucleophilic trapping of 3-homoadamantyl cation (94:6 for the reaction with acetate ion): Nordlander, J. E.; Jindal, S. P.; Schleyer, P. v. R.; Fort, Jr. R. C.; Harper, J. J.; Nicholas, R. D. J. Am. Chem. Soc. 1966, 89, 4475.

44. Liggero, S. H.; Sustmann, R.; Schleyer, P. v. R. J. Am. Chem. Soc. 1969, 91, 4571.

45. Krapcho, A. P.; Johanson, R. G. J. Org. Chem. 1971, 36, 146. 
46. Krasutsky, P. A.; Kolomitsyn, I. V.; Carlson, R. M. Org. Lett. 2001, 3, 2997.

47. Krasutsky, P.A.; Kolomitsyn, I. V.; Carlson, R.; Hong, W. U.S. Patent Application June 5, 2002, Serial No. 10/163,840.

48. Krasutsky, P.A.; Kolomitsyn, I. V.; Carlson, R.; Hong, W. PCT Int. Appl. 2002, CODEN: PIXXD2 WO 2002098924 A2 20021212, 24 pp.

49. (a) Sawada, H. Chem. Rev. 1996, 96, 1779. (b) Sawada, H. J. Fluorine Chem. 2000, 105, 219.

50. Sawada, H.; Kita, M.; Yoshimizu, J.; Kyokane, T.; Kawase, Y.; Hayakawa, K.; Yoshino, J. J. Fluorine Chem. 1997, 92, 51. 